\title{
Different Damaged Shaft Lining Concrete Resistance to Sulfate Corrosion
}

\author{
Xurong Li, Hongguang Ji*, Juanhong Liu and Shuang You \\ School of Civil and Environmental Engineering, University of Science and Technology Beijing, Beijing, China
}

\begin{abstract}
Shaft lining concrete itself has a certain degree of initial damage before being corroded by sulfate. In order to study the resistance of the concrete of the initial damage in different corrosion solution concentration of sulfate, samples of concrete without initial damage, loaded $50 \%$ ultimate load and loaded $70 \%$ ultimate load with initial damage concrete were selected and studied their corrosion resistance in $9 \%, 12 \%$ and $15 \%$ concentrations of sulfate solution. The results show that compared with concrete with no initial damage, the concrete with initial damage resistance to sulfate corrosion is varied. With the increased concentration of the corrosion solution, the concrete with worse initial damage exhibited much lower resistance to sulfate corrosion.
\end{abstract}

Keywords: Concrete, damage, sulfate.

\section{INTRODUCTION}

Sulfate attack is one of the main factors of causing the failure of concrete, resulting in degradation of the performance of concrete structure and the service life being shortened $[1,2]$. Some of the concrete structures constructed in the world have failure phenomenon because of sulfate attack $[3,4]$. Therefore, some scholars have initiated the research of concrete resistance to sulfate corrosion, but the researches are for the resistance to sulfate corrosion of the concrete with no initial damage [5-8]. There are fewer studies for the performance of the concrete with initial damage under sulfate attack. However, in practical engineering, many factors will lead to concrete structure experiencing initial damage of different degree before suffering sulfate attack. Therefore, it is necessary to study the concrete with initial damage for the resistance to sulfate corrosion. This paper is based on the background of practical engineering and the main research is the ability of different initially damaged concrete for resistance to sulfate corrosion of different concentrations. It can provide theoretical basis for evaluating concrete damage in sulfate environment of practical engineering.

Linhuan Coal Mine was completed and put into operation in December 1985. It contains four shafts; main shaft, auxiliary shaft and two air shafts. The water point of auxiliary shaft is located in the main bedrock section and some water points were located at the fourth aquifer. Bedrock section of the shaft lining appears sulfate corroded by sulfate various degrees by field investigation. The concrete strength of some parts is lower than the design strength and to test by the rebound method, they need repairs. Shaft lining concrete has the initial damage because of load in the construction process. The damage of the shaft lining concrete structure in sulfate environment is more serious because of the initial damage of concrete. In order to simulate the actual working

*Address correspondence to this author at the School of Civil and Environmental Engineering, University of Science and Technology Beijing, Beijing, China; Tel: 15652931549; E-mail: dr10dr10@163.com conditions, the mix proportion of the concrete used in the experiment is the mix proportion of the shaft lining concrete in actual practical environment. The concrete was damaged by the pre loading before putting it into sulfate solution. Mass change and relative dynamic modulus of elasticity express concrete resistance to sulfate corrosion in the experiment. The resistance to sulfate corrosion with no initial damage of the concrete, loaded $50 \%$ ultimate load and loaded $70 \%$ ultimate load with initial damage concrete was studied. The experimental results have certain reference significance for durability assessment and life prediction of damaged shaft lining concrete structure in the sulfate environment.

\section{EXPERIMENTAL DESIGN}

Test raw materials: P.O42.5 cement, the main performance index of the cement is shown in Table 1. Natural sand, apparent density is $2513 \mathrm{~kg} / \mathrm{m}^{3}$, the bulk density is $1556 \mathrm{~kg} / \mathrm{m}^{3}$, the porosity is $38.1 \%$, belongs to the second zone in the sand. Limestone, apparent density is $2761 \mathrm{~kg} / \mathrm{m}^{3}$, the bulk density is $1443 \mathrm{~kg} / \mathrm{m}^{3}$, crush index is $5 \%$, mud content is $1.3 \%$. C30 concrete mix sees Table 2 .

Sulfate solution of $9 \%, 12 \%$ and $15 \%$ concentration was mixed according to $4: 1$ of the mass ratio of magnesium sulfate and sodium sulfate. The specimens are $100 \mathrm{~mm} \times$ $100 \mathrm{~mm} \times 100 \mathrm{~mm}$ cubes. Specimen grouping is shown in Table 3. The specimens were stirred by forced action mixer and compacted by shaking table. Form removal was carried out after 24 hours. The specimens were cured in the standard curing room for 28 days. The compressive strength, ultrasonic testing and quality of the group of specimens (three specimens) is measured after curing 28 days and was taken the average. Eighty-four specimens of no initial damage specimens were put into the water with sulfate solution of $9 \%, 12 \%$ and $15 \%$ concentration. Eighty-four specimens were loaded $50 \%$ ultimate load and then unloaded and measured their compressive strength performed ultrasonic testing and quality, finally, they were put into the water with sulfate solution of $9 \%, 12 \%$ and $15 \%$ concentrations. Eighty-four specimens were loaded $70 \%$ ultimate load, and 


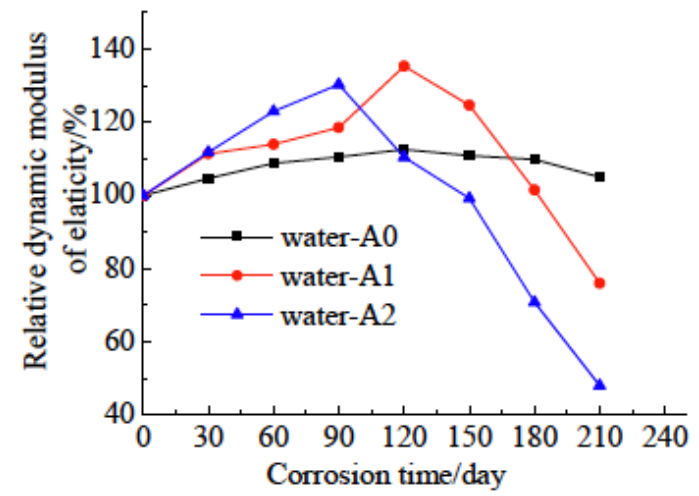

(a)

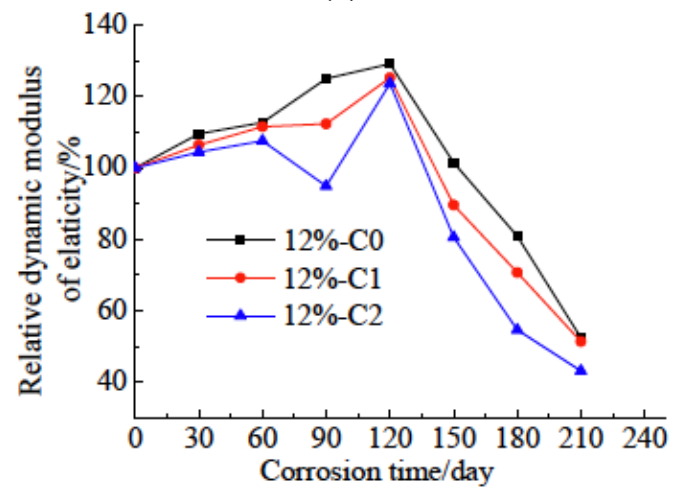

(c)

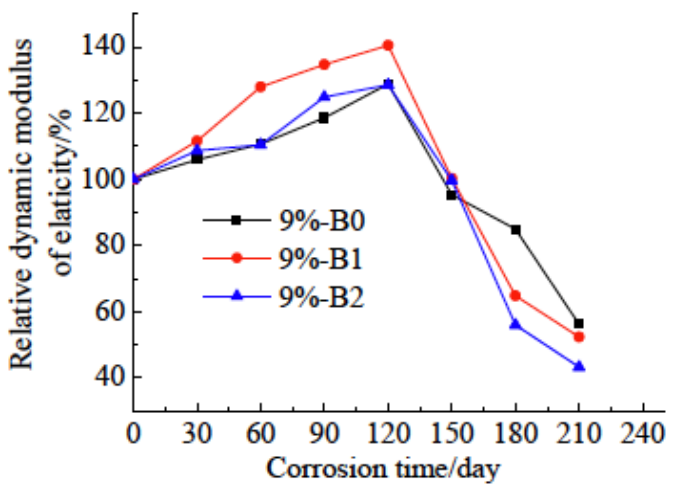

(b)

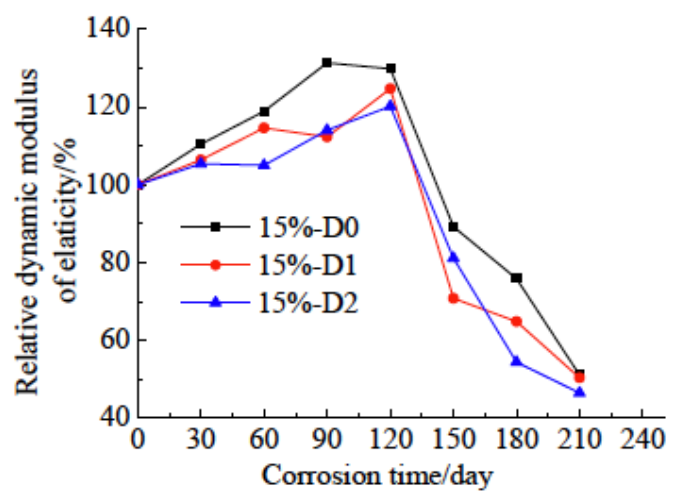

(d)

Fig. (1). Comparison of relative dynamic modulus of elasticity of different initial damage specimens in water and different concentration corrosion solution after one to seven months.

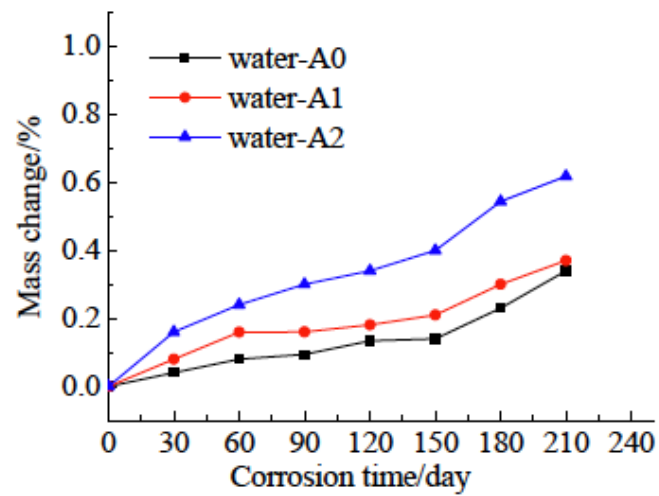

(a)

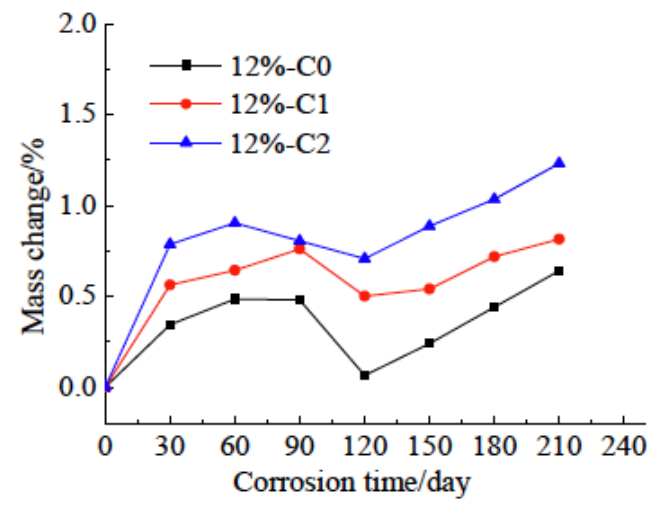

(c)

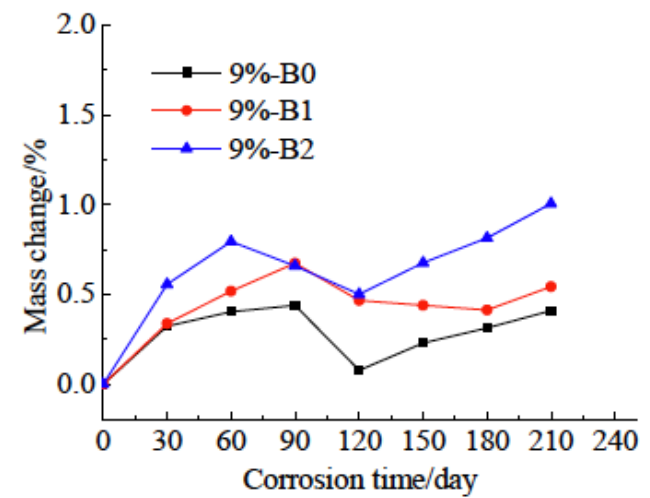

(b)

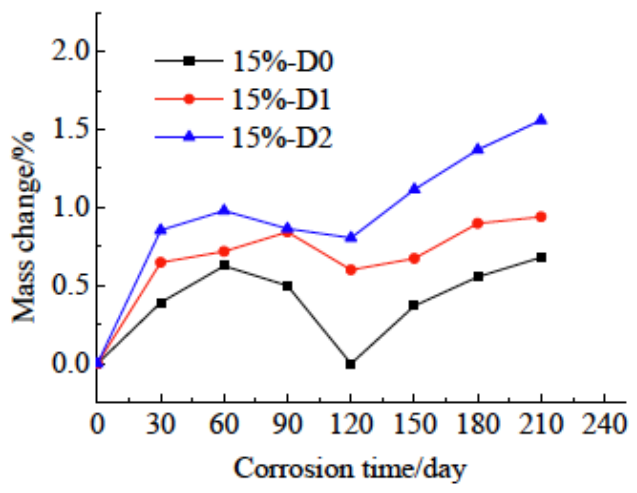

(d)

Fig. (2). Comparison of mass change of different initial damage specimens in water and different concentration corrosion solution after one to seven months. 
concentration sulfate solution, quality increase more and more. The main reason of this phenomenon lies in the following stages: the first stage of concrete hydration process, calcium hydroxide etc hydration products dissolved quantity is less than the invasion of sulfate ions. The second stage, stripping amount is greater than the invasion. The third stage, with the increase of corrosion time of sulfate solution, ettringite and gypsum fills the pore. The reaction products in concrete gradually increase and the increased amount is more than the scaled mass in the concrete test, so quality of the concrete specimen increases again.

\section{ANALYSIS OF MICRO MECHANISM}

The influence of sulfate solution and the initial damage for concrete material can be obtained by a macro test. The corrosion resistance of concrete material depend on its microstructure and in order to further study the influence of sulfate solution and the initial damage to concrete material on the microstructural level a Scanning Electron Microscope, SEM, analysis is under taken. Specimens of representative were selected. They are without initial damage concrete specimens and loaded $50 \%$ ultimate load with initial damage concrete specimens in water and in sulfate solution for seven months. Selected site is fracture surface of the specimen, the surface corrosion area (far from section), and internal area (far from section). SEM results are shown in Figs. (3-5).

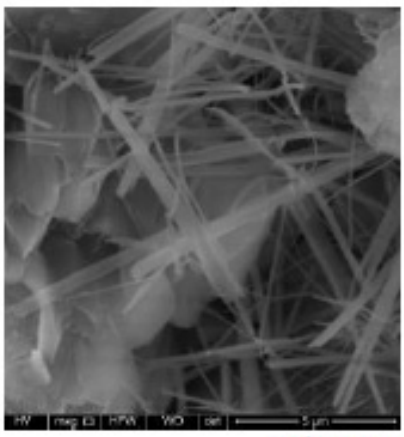

a(water-A0)

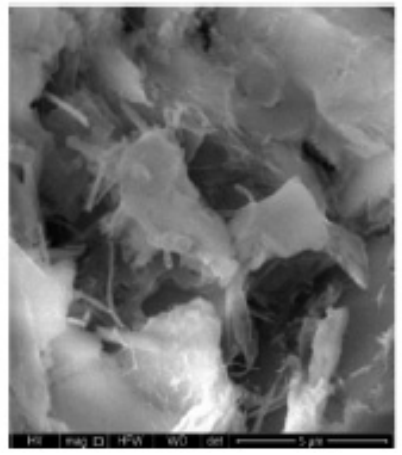

c(12\%-C0)

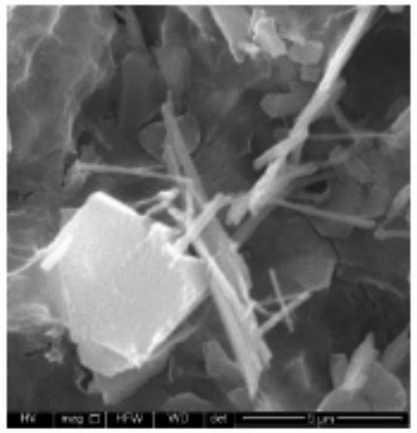

b(wate-A2)

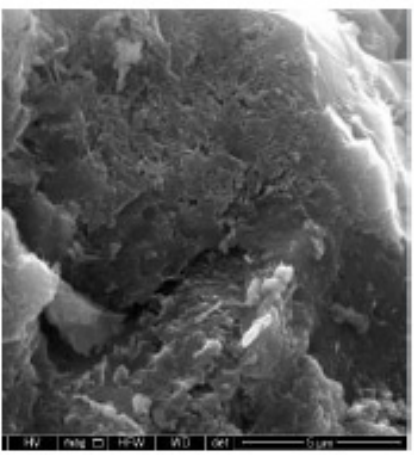

d(12\%-C2)
Fig. (3). SEM image of fracture surface of specimens.

The Figs. (3, 4 and 5) shows that sulfate ions infiltrates and diffuses along the long crack and pore of concrete and reach concrete relatively weak region and at the same time the hydration products of cement cause chemical reaction and produces the expanding erosion products. Erosion prod- ucts first fill cracks and porosity of concrete, if the crack and pore are filled as the time goes on, erosion products of the reaction generation will produce swelling stress. If the tensile stress of expansion exceeds the tensile strength of the concrete itself, macroscopic performance will be affected and the concrete would expand, RDME and strength will be reduced. Sulfate ions enter into the concrete but the driving force is relatively small when the concentration of corrosion solution is low, so the content of sulfate ions in concrete are low, the erosion thickness is relatively small and effective bearing area is relatively large. The macroeconomic performance is slightly affected with slight deterioration of strength and the RDME is relatively large. If the initial damage is more severe, the accelerating effects of sulfate ion intrusion are more obvious in the same concentration corrosion solution. The macroeconomic performance show severe strength deterioration and the RDME decreases significantly.

Microscopic test of sections both external and internal of the specimens can provide strong evidence for the macro test data and mechanism analysis and further validates the macro test result.

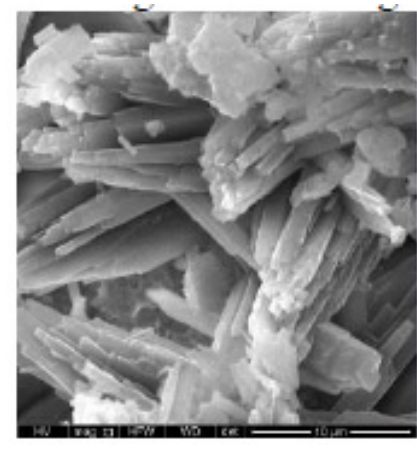

a(wate-A0)

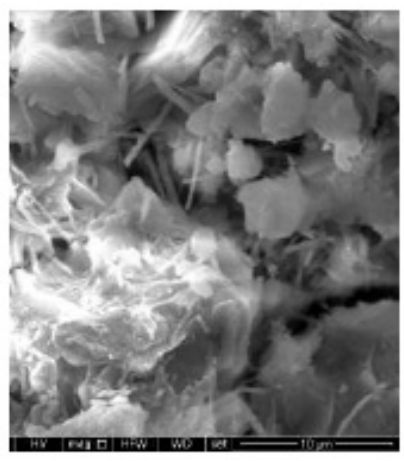

c(12\%-C0)

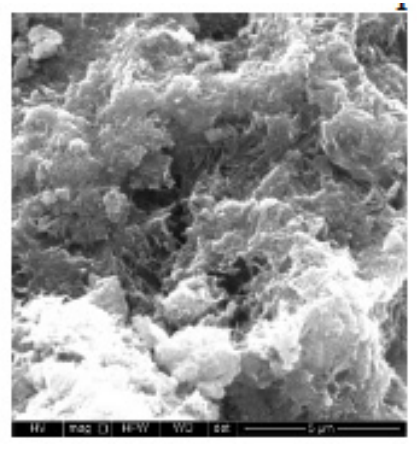

b(wate-A2)

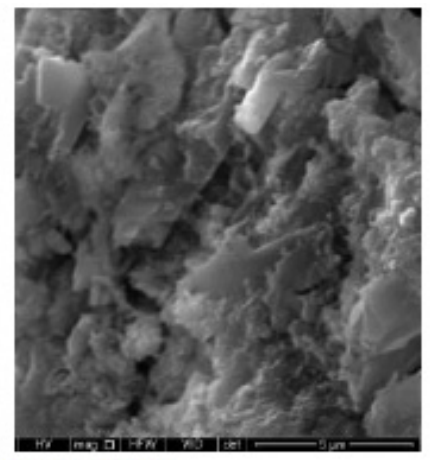

d(12\%-C2)
Fig. (4). SEM image of the surface corrosion area of specimens.

\section{CONCLUSION}

(1) The resistance to sulfate attack of the initial damage concrete is worse compared to concrete without initial damage. The initial damage accelerates the process of sulfate corrosion.

(2) The resistance to sulfate attack of concrete decreases with increase of the corrosion solution concentration increases for similar concrete specimens. 
(3) The resistance to sulfate attack to concrete decreases when the initial damage increases with the same concentration sulfate solution.
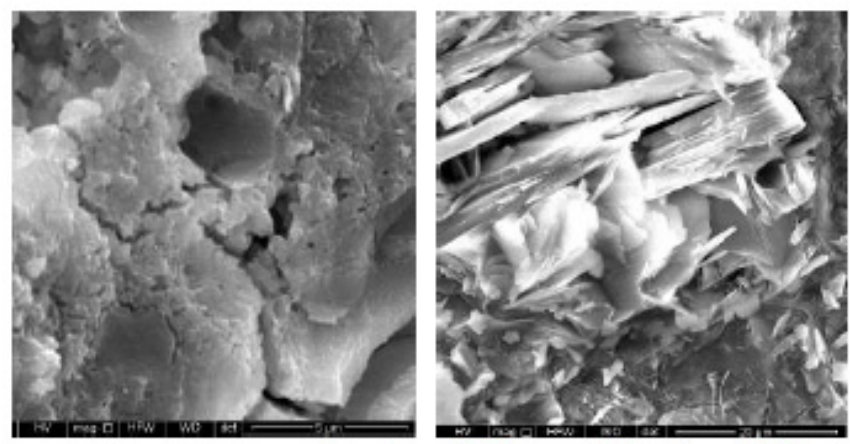

a(wate-A0)

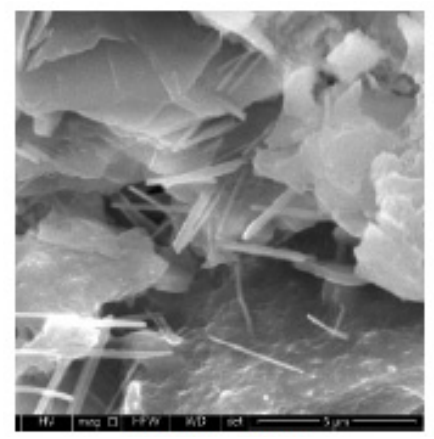

c(12\%-C0)
b(wate-A2)

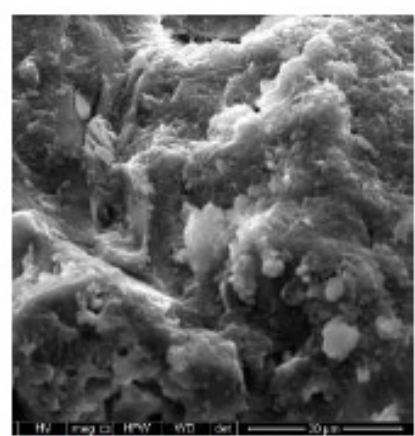

d(12\%-C2)

\section{CONFLICT OF INTEREST}

The authors confirm that this article content has no conflict of interest.

\section{ACKNOWLEDGEMENTS}

Project supported by national natural science foundation project of china 51174015 .

\section{REFERENCES}

[1] H. Teng, F. Huang, and D. Ma, "Discussion on Durability of Concrete Exposed to Functions of Multiple Factors Containing Sulfate", Arch. Technol., vol. 41, no. 9, pp. 834-836, 2010.

[2] X. Zuo, and W. Sun, "Full process analysis of damage and failure of concrete subjected to external sulfate attack" J. Chinese Ceramic Soci., vol. 37, no. 7, pp. 1063-1067, 2009.

[3] P. J. M. Monteiro, and K E. Kurtis, "Time to failure for concrete exposed to severe sulfate attack", Cem. Conc. Res., vol. 33, no. 7, pp. 987-993, 2003.

[4] J. Marchand, E. Samsona, and Y. Maltaisa, "Theoretical Analysis of the Effect of Weak Sodium Sulfate Solution the Durability of Concrete", Cem. Conc. Composit., vol. 24, no. 3/4, pp. 317-329, 2002.

[5] Z. Jin, W. Sun, and Y. S. Zhang, "Damage of Concrete in Sulfate and Chloride Solution", J. Chin. Ceramic Soc., vol. 34, no. 5 pp. 630-635, 2006

[6] Y. Liang, and Y. Yuan, "Mechanism of concrete destruction under sodium sulfate and magnesium sulfate solution", J. Chin. Ceramic Soci., vol. 35, no. 4, pp. 504-508, 2007.

[7] B. Guan, S. Chen, and H. Li, "Sulfate corrosion life of cement concrete under fatigue load", J Build. Mat., vol. 15, no. 3 pp. 395 398. 2012.

[8] H. Xu, Z. Chen, and X. Guo, "Physical and mechanical performance and influencing factors of high performance concrete under sulfate attack", J. China Coal Soc., vol. 37, no. 2, pp. 217-220. 2012.

Fig. (5). SEM image of internal area of specimens.

Received: September 30, 2014

Revised: October 24, 2014

Accepted: October 25, 2014

(C) Li et al.; Licensee Bentham Open.

This is an open access article licensed under the terms of the Creative Commons Attribution Non-Commercial License (http://creativecommons.org/licenses/by-nc/3.0/) which permits unrestricted, non-commercial use, distribution and reproduction in any medium, provided the work is properly cited. 